\title{
Produção agroeconômica de taro em função do número de amontoas
}

\section{Agroeconomic yield of Taro clones in function of number of hilling operation}

\author{
Néstor Antonio Heredia Zárate ${ }^{1 *}$; Maria do Carmo Vieira²; \\ Luciane Almeri Tabaldi ${ }^{3}$; Rosimeire Pereira Gassi ${ }^{4}$; \\ André Makio Kusano ${ }^{5}$; Arthur Keiji Mendes Maeda
}

\section{Resumo}

Mais de 800 espécies de Araceae têm importância econômica (ornamental, alimentícia ou medicinal) ou etnobotânica, e cerca de $10 \%$ da população mundial utiliza os rizomas de taro (Colocasia esculenta (L.) Schott) na alimentação. Avaliou-se a produção agroeconômica dos clones de taro Chinês e Macaquinho, cultivados sem amontoa; com uma amontoa, aos 58 dias após o plantio - DAP ou com duas amontoas, aos 58 e 86 DAP, nas condições ambientais de Dourados-MS. A colheita foi aos 202 DAP. Foram realizadas análises agronômica e econômica. As plantas do taro 'Chinês' apresentaram 123,5\% a mais de massas fresca e $86,9 \%$ a mais de massa seca de folhas que as do 'Macaquinho'. As massas frescas de rizoma-mãe - RM, rizoma-filho comercia l- RFC e rizoma-filho não-comercial - RFNC das plantas do taro 'Macaquinho' foram maiores em 24,9\%, 193,8 e 19,4\%, respectivamente, do que as das plantas do 'Chinês'. Não houve influência dos tratamentos relacionados com a amontoa sobre as produções de massas frescas e secas de RM, RFC e RFNC. Ao comparar a renda líquida obtida concluiu-se que o clone Macaquinho foi melhor quando cultivado com duas amontoas porque induziu aumento de R\$ 6.784,6 e de R $\$ 11.181 .2$ em relação ao cultivo com uma amontoa e sem amontoa, respectivamente.

Palavras-chave: Colocasia esculenta, clones, trato cultural, renda

\begin{abstract}
More than 800 species of Araceae have economic (ornamental, edible or medicinal) or ethnobotanic importance, and about $10 \%$ of the world population use taro rhizome (Colocasia esculenta (L.) Schott) in feeding. The agroeconomic yield of Chinês and Macaquinho taro clones was evaluated, when cultivated without hilling operation and under one hilling at 58 days after planting - DAP, and under two hillings, at 58 and 86 DAP, in the environment conditions of Dourados-MS. Harvest was carried at 202 DAP, when agronomic and economic analysis were performed. 'Chinês' taro plants presented $123.5 \%$ and $86.9 \%$ higher results for fresh and dry weight of leaves, respectively, when compared to Macaquinho clone. Fresh weight of corms-RM, commercial cormel-RFC and noncommercial cormelRFNC of 'Macaquinho' taro plants were respectively $24.9 \%, 193.8 \%$ and $19.4 \%$ statistically superiors than 'Chinês' taro plants. There was no significant difference of treatments among hilling operations on fresh and dry weight productions of RM, RFC and RFNC. Comparing net incomes, Macaquinho clone
\end{abstract}

\footnotetext{
1 Prof. Associado III e Bolsista de Produtividade em Pesquisa do CNPq. Universidade Federal da Grande Dourados, Faculdade de Ciências Agrárias, UFGD, Dourados, MS. E-mail: nahz@terra.com.br

2 Prof ${ }^{a}$ Titular e Bolsista de Produtividade em Pesquisa do CNPq. UFGD. Dourados, MS. E-mail: vieiracm@terra.com.br

3 Bacharel em Ciências Biológicas. Bolsista de Desenvolvimento Científico Regional FUNDECT/UFGD. UFGD. Dourados, MS. E-mail: lutabaldi@yahoo.com.br

4 Eng $^{\circ}$ Agro ${ }^{\circ}$ Pós-doutoranda do CNPq. UFGD, Dourados, MS. E-mail: rpgassi@yahoo.com.br

5 Discente(s) de Graduação do Curso de Agronomia, UFGD, Dourados-MS, Bolsista de PIBIC/CNPq/UFGD. E-mail: andremakiokusano@gmail.com; arthur_maeda@hotmail.com

* Autor para correspondência
} 
plants had better results when grown under two hilling operations, inducing increases of $\mathrm{R} \$ 6,784.6$ and $\mathrm{R} \$ 11,181.2$ for cultivation with one hilling and without it, respectively.

Key words: Colocasia esculenta, clones, cultivation, income

\section{Introdução}

Devido às características de rusticidade e valor nutricional, o taro (Colocasia esculenta (L.) Schott) é uma espécie tuberosa sugerida pela FAO (Food and Agriculture Organization) como alternativa para aumento da base alimentar em países em desenvolvimento (PEREIRA et al., 2004). A produção mundial já atingiu 11.267 mil toneladas e produtividade de $6,9 \mathrm{t} \mathrm{ha}^{-1}$, distribuídas em 1.633 mil ha (FAOSTAT, 2009). A espécie é utilizada na agricultura de clima tropical, por ser alimento rico em amido, destacando-se como cultura de baixo custo de produção, fácil conservação, pouca exigência em fertilidade do solo e insumos (HEREDIA ZÁRATE et al., 2009a).

No Brasil, as produções médias de rizomas-filho comerciais de taro estão entre $12 \mathrm{t} \mathrm{ha}^{-1}$ e $20 \mathrm{t} \mathrm{ha}^{-1}$ (HEREDIA ZÁRATE et al., 2004). sendo cultivados os clones Chinês, Japonês e Macaquinho em Minas Gerais (GONDIM et al., 2007). Branco, Chinês, Japonês, Rosa e Roxo no Rio de Janeiro (OLIVEIRA et al., 2004; 2008, SILVA et al., 2006). O estado do Espírito Santo destaca-se como tradicional produtor predominando os clones Chinês e São Bento, com produtividade, superior à dos demais (CARMO; PUIATTI, 2004). Os melhores rizomas-filho para comercialização apresentam 100 a 200 gramas cada (KUROSAWA, 2009).

A amontoa depende da espécie, do estágio de crescimento das plantas e da forma de realização, se manual ou mecanizada (HEREDIA ZÁRATE; VIEIRA, 2005). Esta prática é questionada sobre sua necessidade e época de realização, havendo poucos resultados relacionados em função de ser uma prática "corriqueira" nos tratos culturais de algumas hortaliças (PUIATTI et al., 2005).

No cultivo do taro, como forma de obter alta produtividade e rizomas-filho de maior tamanho, sem onerar o custo de produção, têm-se sugerido a realização de leves amontoas durante as capinas (MELO et al., 2009). Puiatti et al. (2005) recomendaram uma amontoa aos 120 dias após o plantio.

Além do conhecimento do custo operacional total, torna-se necessário conhecer a participação relativa dos itens do custo operacional efetivo. Igualmente importante, conhecer a estrutura dos custos fixos, ou dispêndios indiretos, sem os quais o cálculo da lucratividade fica prejudicado (MELO et al., 2009).

Em função do exposto, o objetivo principal deste trabalho foi avaliar a produção agroeconômica de clones de taro cultivados sob diferentes números de amontoas em Dourados-MS.

\section{Material e Métodos}

O trabalho foi conduzido no Horto de Plantas Medicinais da Faculdade de Ciências Agrárias (FCA), da Universidade Federal da Grande Dourados (UFGD), em Dourados-MS, situado nas coordenadas latitude: $22^{\circ} 11^{\prime} 44^{\prime \prime}$, longitude: $54^{\circ} 56^{\prime} 07^{\prime \prime} \mathrm{W}$ e altitude de $452 \mathrm{~m}$. O clima do município de Dourados, segundo a classificação de Köppen é Mesotérmico Úmido; do tipo Cwa, com temperaturas e precipitações médias anuais variando de 20 a $24^{\circ} \mathrm{C}$ e de 1250 a $1500 \mathrm{~mm}$.

O solo da área de cultivo é do tipo Latossolo Vermelho Distroférrico de textura muito argilosa, com as características químicas: 5,9 de $\mathrm{pH}$ em $\mathrm{H}_{2} \mathrm{O}$; 28,9 $\mathrm{g} \mathrm{dm}^{-3}$ de M.O.; 38,0 $\mathrm{mg} \mathrm{dm}^{-3}$ de P; 0,0; 3,5; 46,$0 ; 22,0 ; 53,0 ; 71,5$ e $124,5 \mathrm{mmol}_{\mathrm{c}} \mathrm{dm}^{-3}$ de $\mathrm{Al}^{+3}$, $\mathrm{K}, \mathrm{Ca}, \mathrm{Mg}, \mathrm{H}+\mathrm{Al}, \mathrm{SB}$ e CTC, respectivamente e $57,0 \%$ de saturação por bases. Na parte física, os resultados da análise granulométrica mostraram que o solo era composto por $8 \%$ de areia grossa, $13 \%$ de areia fina, $16 \%$ de silte e $63 \%$ de argila. 
Foram estudados os clones Chinês e Macaquinho cultivados: sem amontoa; com uma amontoa efetuada aos 58 dias após o plantio-DAP; e com duas amontoas, sendo a primeira efetuada aos 58 dias após o plantio-DAP e a segunda aos 86 DAP. Os tratamentos foram arranjados no esquema fatorial $2 \times 3$, no delineamento experimental de blocos casualizados, com seis repetições. As parcelas tiveram área total de 4,5 $\mathrm{m}^{2}(3,0 \mathrm{~m} \times$ $1,50 \mathrm{~m})$ e área útil de $3,0 \mathrm{~m}^{2}(3,0 \mathrm{~m} \times 1,00 \mathrm{~m})$. Os espaçamentos foram de $0,20 \mathrm{~m}$ entre plantas; 0,60 $\mathrm{m}$ entre fileiras simples dentro do canteiro e 0,90 $\mathrm{m}$ entre fileiras duplas, perfazendo população de 66.000 plantas ha $^{-1}$.

O solo da área do experimento foi preparado com aração, gradagem e elevação de canteiros com rotoencanteirador. No dia do plantio, foram abertos dois sulcos de plantio com aproximadamente 0,05 $\mathrm{m}$ de largura $\mathrm{x} 0,05 \mathrm{~m}$ de profundidade, onde foram alocadas as mudas, compostas de rizomas-filho inteiros, com massas médias de 20,7 g para o clone Chinês e de 18,8 g para o 'Macaquinho'. Não foi utilizada nenhuma técnica de adubação durante o ciclo da cultura. As irrigações foram por aspersão, com turnos de rega diários até 60 dias após o plantio e a cada dois dias após esse período até a colheita. A vegetação espontânea foi controlada por capinas entre parcelas e manual dentro das parcelas. Não foram registrados danos por pragas e ou doenças.

A colheita das plantas foi realizada aos 202 DAP, quando mais de $50 \%$ das folhas apresentavam amarelecimento como sintomas de senescência. Foram avaliadas as massas fresca e seca das folhas (limbo + pecíolo), rizomas-mãe, rizomas-filho comerciais (com massa superior a $25 \mathrm{~g}$ ) e rizomasfilho não comerciais. Para obtenção da massa seca, os materiais vegetais foram seccionados, distribuídos em sacos de papel e colocados em estufa com circulação forçada de ar, a $60^{\circ} \mathrm{C} \pm$ $5^{\circ} \mathrm{C}$, até massa constante. Os dados obtidos foram submetidos à análise de variância (SAEG, 2007) e as médias comparadas pelo teste de Tukey, a 5\% de probabilidade.

A análise econômica foi efetivada conforme cálculo sugerido por Heredia Zárate, Casali e Alvarez Venegas (1994), para o taro e por Terra et al. (2006), para o milho doce (Zea mays L.), determinar custos variáveis (insumos, mão-deobra e aluguel de maquinários), fixos (aluguel da terra e benfeitorias) reserva para imprevistos, administração e juros do capital. Para o cálculo da renda bruta, utilizou-se o valor de $\mathrm{R} \$ 1,20 \mathrm{~kg}^{-1}$ (média dos preços pagos no varejo aos produtores de Dourados-MS, pelo quilograma dos rizomasfilho comerciais) e posteriormente, efetuaram-se as conversões por hectare com as produções obtidas em cada tratamento. A renda líquida foi calculada pela subtração dos custos de produção em relação à renda bruta.

\section{Resultados}

\section{Análise agronômica}

As massas frescas e secas (Tabela 1) de folhas, rizomas-mãe (RM), rizomas-filho comerciais (RFC) e rizomas-filho não-comerciais (RFNC) não foram influenciados significativamente pela interação clones e amontoas. Os clones influenciaram as massas frescas e secas de folhas, RM, RFC e RFNC e as amontoas influenciaram as massas frescas e secas de folhas. Esses resultados indicam que houve respostas modificativas que adaptaram as plantas às condições ambientes, durante o seu período de crescimento (LARCHER 2004). 
Tabela 1. Massas frescas e secas de folhas, rizomas-mãe (RM), rizomas-filho comerciais (RFC) e rizomas-filho (RFNC) não comerciais de clones de taro em função do número de amontoas.

\begin{tabular}{lcccccccc}
\hline & \multicolumn{4}{c}{ Massa fresca $\left(\mathrm{t} \mathrm{ha}^{-1}\right)$} & \multicolumn{4}{c}{ Massa seca $\left(\mathrm{t} \mathrm{ha}^{-1}\right)$} \\
\cline { 2 - 9 } & Folha & RM & RFC & RFNC & Folha & RM & RFC & RFNC \\
\hline Clones & & & & & & & & \\
\hline Chinês & $17,7 \mathrm{a}^{*}$ & $4,4 \mathrm{~b}$ & $9,2 \mathrm{~b}$ & $7,7 \mathrm{~b}$ & $1,6 \mathrm{a}$ & $1,2 \mathrm{a}$ & $2,5 \mathrm{~b}$ & $2,1 \mathrm{a}$ \\
Macaquinho & $7,9 \mathrm{~b}$ & $5,5 \mathrm{a}$ & $27,0 \mathrm{a}$ & $9,2 \mathrm{a}$ & $0,8 \mathrm{~b}$ & $0,9 \mathrm{~b}$ & $4,8 \mathrm{a}$ & $1,7 \mathrm{~b}$ \\
\hline Número de amontoas & & & & & & & & \\
\hline \multicolumn{1}{c}{0} & $13,2 \mathrm{ab}$ & $4,8 \mathrm{a}$ & $16,5 \mathrm{a}$ & $7,8 \mathrm{a}$ & $1,3 \mathrm{ab}$ & $1,1 \mathrm{a}$ & $3,5 \mathrm{a}$ & $1,8 \mathrm{a}$ \\
1 & $14,6 \mathrm{a}$ & $5,1 \mathrm{a}$ & $16,7 \mathrm{a}$ & $8,9 \mathrm{a}$ & $1,3 \mathrm{a}$ & $1,2 \mathrm{a}$ & $3,3 \mathrm{a}$ & $1,9 \mathrm{a}$ \\
\multicolumn{1}{c}{ C.V. $(\%)$} & $10,6 \mathrm{~b}$ & $4,9 \mathrm{a}$ & $21,0 \mathrm{a}$ & $8,8 \mathrm{a}$ & $1,0 \mathrm{~b}$ & $1,0 \mathrm{a}$ & $4,2 \mathrm{a}$ & $2,0 \mathrm{a}$ \\
\hline
\end{tabular}

*Médias seguidas das mesmas letras minúsculas, nas colunas, não diferem estatisticamente entre si, pelo teste F para clones e pelo teste de Tukey para amontoas, a 5\% de probabilidade.

Fonte: Elaboração dos autores

As plantas do taro 'Chinês' apresentaram aumentos de $123,5 \%$ de massas fresca e $86,9 \%$ de massa seca de folhas em relação às plantas do 'Macaquinho'. Essas diferenças de produção ocorreu porque as plantas dos diferentes clones apresentam taxas variáveis de crescimento e morfologia bem características, com modificações no final do ciclo vegetativo, em razão de fatores ambientes, mas com padrão de resposta dependente do componente genético (HEREDIA ZÁRATE et al., 2003b). Isso se mostra coerente com os resultados de Helmich (2010), que estudando os clones de taro Chinês, Macaquinho, Japonês e Cascudo, obtiveram produção do taro Chinês superando em $9,46 \mathrm{tha}^{-1}$ à do clone Macaquinho.

A massa fresca de folhas das plantas com uma amontoa foi semelhante à massa das cultivadas sem amontoa e superaram as das plantas com duas amontoas. Isso sugere que os sistemas vegetais têm mecanismos de autoregulacão, baseados na capacidade de adaptacão do organismo individual e das populacões ou no equilíbrio das relacões de interferência, como competicão por nutrientes e água (LARCHER, 2004; TAIZ; ZEIGER, 2004).

As massas frescas do taro 'Macaquinho' foram superiores as plantas do 'Chinês' e mostraram relação inversa à produção de folhas. Esses resultados confirmam que os genótipos diferentes variaram no tempo para alcançar a maturidade (HEREDIA ZÁRATE; VIEIRA; FACCO, 2003a) e permitindo levantar a hipótese de que a quantidade de fotossintatos armazenados nas folhas podem ser translocados para os rizomas-mãe e destes para os rizomas-filhos, quando as folhas iniciam a senescência. Isso porque, as plantas podem apresentar taxas distintas de crescimento e morfologia, com modificações no final do ciclo vegetativo, em razão de fatores ambientais (HEREDIA ZÁRATE et al., 2009b).

As massas secas de RM e de RFNC das plantas do taro 'Chinês' superaram às massas do 'Macaquinho' e mostraram relação direta com as massas fresca e seca de folhas mas, a massa seca de RFC foi menor que a do 'Macaquinho'. Esses comportamentos sugerem que os rizomas-mãe já tinham alcançado a maturidade e o máximo crescimento, com provável aumento da translocação dos fotoassimilados da parte aérea para os RM e destes diretamente para os rizomas-filho ou que houve equilíbrio de translocação no tempo, entre a parte aérea e os rizomas.

A falta de influência dos tratamentos relacionados com a amontoa sobre as produções de massas frescas e secas de RM, RFC e RFNC mostra que a amontoa comportou-se como um fator neutro. Também pode dever-se aos altos valores de C.V. 
que foram encontrados, especialmente para RFC e que devem ser função de variações na translocação de fotossintatos de reserva nas plantas induzindo respostas produtivas desuniformes dentro dos blocos, que aumentaram os valores de C.V. Isso porque, embora a planta inteira de taro seja autotrófica, seus órgãos individuais são heterotróficos, dependendo uns dos outros para obter nutrientes e fotossintatos (HEREDIA ZÁRATE et al., 2004).

\section{Análise econômica}

O custo total estimado para produzir $1,0 \mathrm{ha}^{-1} \mathrm{de}$ taro variou em $\mathrm{R} \$ 176,3$ entre o cultivo dos clones Chinês e Macaquinho e em R $\$ 734,7$ (Tabelas 2 e 3 ) entre o menor e o maior custo correspondentes ao cultivo sem amontoa e com duas amontoas. A diferença dos custos totais entre os clones teve relação direta com o gasto de $120 \mathrm{~kg}$ a mais de massa de mudas do taro 'Chinês'.

Tabela 2. Custos de produção de um hectare de taro 'Chinês', sob diferentes números de amontoas.

\begin{tabular}{|c|c|c|c|c|c|c|}
\hline \multirow{3}{*}{ Componentes } & \multicolumn{6}{|c|}{ Número de amontoas } \\
\hline & \multicolumn{2}{|c|}{0} & \multicolumn{2}{|c|}{1} & \multicolumn{2}{|c|}{2} \\
\hline & Quantidade & Custo (R\$) & Quantidade & Custo (R\$) & Quantidade & Custo $(\mathrm{R} \$)$ \\
\hline \multirow{2}{*}{\multicolumn{7}{|c|}{$\begin{array}{l}\text { 1. Custos Variáveis } \\
\text { Insumos }\end{array}$}} \\
\hline & & & & & & \\
\hline Mudas & $1363 \mathrm{~kg}$ & $1.636,0$ & $1363 \mathrm{~kg}$ & $1.636,0$ & $1363 \mathrm{~kg}$ & $1.636,0$ \\
\hline \multicolumn{7}{|l|}{ Mão-de-obra } \\
\hline Plantio & $12 \mathrm{D} \mathrm{H}^{-1}$ & 360,0 & $12 \mathrm{D} \mathrm{H}^{-1}$ & 360,0 & $12 \mathrm{D} \mathrm{H}^{-1}$ & 360,0 \\
\hline Amontoa & $0 \mathrm{D} \mathrm{H}^{-1}$ & 0,0 & $16 \mathrm{D} \mathrm{H}^{-1}$ & 480,0 & $32 \mathrm{D} \mathrm{H}^{-1}$ & 960,0 \\
\hline Irrigação & $12 \mathrm{D} \mathrm{H}^{-1}$ & 360,0 & $12 \mathrm{D} \mathrm{H}^{-1}$ & 360,0 & $12 \mathrm{D} \mathrm{H}^{-1}$ & 360,0 \\
\hline Capinas & $18 \mathrm{D} \mathrm{H}^{-1}$ & 540,0 & $12 \mathrm{D} \mathrm{H}^{-1}$ & 360,0 & $6 \mathrm{D} \mathrm{H}^{-1}$ & 180,0 \\
\hline \multirow[t]{2}{*}{ Colheita } & $30 \mathrm{D} \mathrm{H}^{-1}$ & 900,0 & $30 \mathrm{D} \mathrm{H}^{-1}$ & 900,0 & $30 \mathrm{D} \mathrm{H}^{-1}$ & 900,0 \\
\hline & $72 \mathrm{D} \mathrm{H}^{-1}$ & $2.160,0$ & $82 \mathrm{D} \mathrm{H}^{-1}$ & $2.460,0$ & $92 \mathrm{D} \mathrm{H}^{-1}$ & $2.760,0$ \\
\hline \multicolumn{7}{|l|}{ Maquinários } \\
\hline Bomba de irrigação & $56,0 \mathrm{~h}$ & 560,0 & $56,0 \mathrm{~h}$ & 560,0 & $56,0 \mathrm{~h}$ & 560,0 \\
\hline \multirow[t]{2}{*}{ Trator } & $4,0 \mathrm{~h}$ & 240,0 & $4,0 \mathrm{~h}$ & 240,0 & $4,0 \mathrm{~h}$ & 240,0 \\
\hline & $60,0 \mathrm{~h}$ & 800,0 & $60,0 \mathrm{~h}$ & 800,0 & $60,0 \mathrm{~h}$ & 800,0 \\
\hline Subtotal $1(\mathrm{R} \$)$ & & $4.596,0$ & & $4.896,0$ & & $5.196,0$ \\
\hline \multicolumn{7}{|l|}{ 2. Custos Fixos } \\
\hline Benfeitoria & 202 dias & 303,0 & 202 dias & 303,0 & 202 dias & 303,0 \\
\hline Remuneração da terra & 1,0 ha & 140,0 & 1,0 ha & 140,0 & 1,0 ha & 140,0 \\
\hline Subtotal $2(\mathrm{R} \$)$ & -- & 443,0 & -- & 443,0 & -- & 443,0 \\
\hline \multicolumn{7}{|l|}{ 3. Outros custos } \\
\hline Imprevistos $(10 \% \mathrm{ST} 1+\mathrm{ST} 2)$ & -- & 503,9 & -- & 533,9 & -- & 563,9 \\
\hline Administração (5\% ST1+ ST2) & -- & 251,9 & -- & 266,9 & -- & 281,9 \\
\hline Subtotal 3 & -- & 755,8 & -- & 800,8 & -- & 845,8 \\
\hline TOTAL & -- & $5.794,4$ & -- & $6.139,4$ & -- & $6.484,4$ \\
\hline Juro trimestral $(2,16 \%)$ & 3 & 375,5 & 3 & 397,8 & 3 & 420,2 \\
\hline TOTAL GERAL & -- & $6.169,9$ & -- & $6.537,2$ & -- & $6.904,6$ \\
\hline
\end{tabular}

Adaptado de Heredia Zárate, Casali e Alvarez Venegas (1994) e Terra et al. (2006).

Custo $\mathrm{D} \mathrm{H}^{-1}=\mathrm{R} \$ 30,0$. Aluguel da terra $\mathrm{ano}^{-1}=240,0$. Hora trator $=\mathrm{R} \$ 60,0$.

Hora bomba irrigação $=\mathrm{R} \$ 10,0$ 
Tabela 3. Custos de produção de um hectare de taro 'Macaquinho', sem e com uma ou duas amontoas.

\begin{tabular}{|c|c|c|c|c|c|c|}
\hline \multirow{3}{*}{ Componentes } & \multicolumn{6}{|c|}{ Número de amontoas } \\
\hline & \multicolumn{2}{|c|}{0} & \multicolumn{2}{|c|}{1} & \multicolumn{2}{|c|}{2} \\
\hline & Quantidade & Custo (R\$) & Quantidade & Custo (R\$) & Quantidade & Custo (R\$) \\
\hline \multicolumn{7}{|l|}{ 1. Custos Variáveis } \\
\hline \multicolumn{7}{|l|}{ Insumos } \\
\hline Mudas & $1243 \mathrm{~kg}$ & $1.491,6$ & $1243 \mathrm{~kg}$ & $1.491,6$ & $1243 \mathrm{~kg}$ & $1.491,6$ \\
\hline \multicolumn{7}{|l|}{ Mão-de-obra } \\
\hline Plantio & $12 \mathrm{D} \mathrm{H}^{-1}$ & 360,0 & $12 \mathrm{D} \mathrm{H}^{-1}$ & 360,0 & $12 \mathrm{D} \mathrm{H}^{-1}$ & 360,0 \\
\hline Amontoa & $0 \mathrm{D} \mathrm{H}^{-1}$ & 0,0 & $16 \mathrm{D} \mathrm{H}^{-1}$ & 480,0 & $32 \mathrm{D} \mathrm{H}^{-1}$ & 960,0 \\
\hline Irrigação & $12 \mathrm{D} \mathrm{H}^{-1}$ & 360,0 & $12 \mathrm{D} \mathrm{H}^{-1}$ & 360,0 & $12 \mathrm{D} \mathrm{H}^{-1}$ & 360,0 \\
\hline Capinas & $18 \mathrm{D} \mathrm{H}^{-1}$ & 540,0 & $12 \mathrm{D} \mathrm{H}^{-1}$ & 360,0 & $6 \mathrm{D} \mathrm{H}^{-1}$ & 180,0 \\
\hline \multirow[t]{2}{*}{ Colheita } & $30 \mathrm{D} \mathrm{H}^{-1}$ & 900,0 & $30 \mathrm{D} \mathrm{H}^{-1}$ & 900,0 & $30 \mathrm{D} \mathrm{H}^{-1}$ & 900,0 \\
\hline & $72 \mathrm{D} \mathrm{H}^{-1}$ & $2.160,0$ & $82 \mathrm{D} \mathrm{H}^{-1}$ & $2.460,0$ & $92 \mathrm{D} \mathrm{H}^{-1}$ & $2.760,0$ \\
\hline \multicolumn{7}{|l|}{ Maquinários } \\
\hline Bomba de irrigação & $56,0 \mathrm{~h}$ & 560,0 & $56,0 \mathrm{~h}$ & 560,0 & $56,0 \mathrm{~h}$ & 560,0 \\
\hline \multirow[t]{2}{*}{ Trator } & $4,0 \mathrm{~h}$ & 240,0 & $4,0 \mathrm{~h}$ & 240,0 & $4,0 \mathrm{~h}$ & 240,0 \\
\hline & $60,0 \mathrm{~h}$ & 800,0 & $60,0 \mathrm{~h}$ & 800,0 & $60,0 \mathrm{~h}$ & 800,0 \\
\hline Subtotal $1(\mathrm{R} \$)$ & & $4.451,6$ & & $4.751,6$ & & $5.051,6$ \\
\hline \multicolumn{7}{|l|}{ 2. Custos Fixos } \\
\hline Benfeitoria & 202 dias & 303,0 & 202 dias & 303,0 & 202 dias & 303,0 \\
\hline Remuneração da terra & 1,0 ha & 140,0 & 1,0 ha & 140,0 & 1,0 ha & 140,0 \\
\hline Subtotal $2(\mathrm{R} \$)$ & -- & 443,0 & -- & 443,0 & -- & 443,0 \\
\hline \multicolumn{7}{|l|}{ 3. Outros custos } \\
\hline Imprevistos (10\% ST1 + ST2) & -- & 489,5 & -- & 519,5 & -- & 549,5 \\
\hline Administração (5\% ST1+ ST2) & -- & 244,7 & -- & 259,7 & -- & 274,7 \\
\hline Subtotal 3 & -- & 734,2 & -- & 779,2 & -- & 824,2 \\
\hline TOTAL & -- & $5.628,8$ & -- & $5.973,8$ & -- & $6.318,8$ \\
\hline Juro trimestral $(2,16 \%)$ & 3 & 364,8 & 3 & 387,1 & 3 & 409,5 \\
\hline TOTAL GERAL & -- & $5.993,6$ & -- & $6.360,9$ & -- & $6.728,3$ \\
\hline
\end{tabular}

Adaptado de Heredia Zárate, Casali e Alvarez Venegas (1994) e Terra et al. (2006).

Custo $\mathrm{D} \mathrm{H}^{-1}=\mathrm{R} \$ 30,0$. Aluguel da terra $\mathrm{ano}^{-1}=240,0$. Hora trator $=\mathrm{R} \$ 60,0$.

Hora bomba irrigação $=\mathrm{R} \$ 10,0$

Do custo total de produção, os custos variáveis representaram em torno de três quartas partes dos valores, tanto no taro 'Chinês' como no 'Macaquinho', para os cultivos sem amontoa e com duas amontoas. A mão-de-obra representou entre $47,0 \%$ e $53,1 \%$ no clone Chinês e entre $48,5 \%$ e $54,6 \%$ no 'Macaquinho'. Esses altos percentuais do valor dos custos de produção relacionados com a mão-de-obra utilizada no cultivo de taro ressaltam a importância da cultura como atividade geradora de emprego no meio rural, por meio do uso de sua mão-de-obra.

Quando se relacionaram os custos dos insumos com o custo total de produção observou-se que o custo das mudas no cultivo sem amontoa foi de $26,5 \%$ no 'Chinês' e de 24,9\% no 'Macaquinho' e no cultivo com duas amontoas os valores foram de 23,7\% no 'Chinês' e 22,2\% no 'Macaquinho'. O gasto com maquinários representou entre 13,0\% e $11,6 \%$ para o 'Chinês' e entre 13,4 e $11,9 \%$ no 
'Macaquinho', para os cultivos sem amontoa e com duas amontoas, respectivamente.

Os custos fixos, em relação ao custo total de produção, representaram entre $7,18 \%$ e $6,42 \%$ no 'Chinês' e entre 7,39\% e 6,58\% no 'Macaquinho', para os cultivos sem amontoa e com duas amontoas. Os outros custos adicionais (imprevistos e administração) representaram $12,25 \%$ do custo total, nos dois clones.

Ao realizar as comparações econômicas observou-se que para o clone Chinês foi melhor o cultivo sem amontoa porque induziria aumento da renda líquida em $\mathrm{R} \$ 1.742,7$ quando relacionada com as rendas obtidas no cultivo com duas amontoas e de $\mathrm{R} \$ 4.699,4$ ao com uma amontoa (Tabela 4). Mas, quando essa maior renda líquida foi comparada com a menor e a maior renda obtida com o 'Macaquinho' observou-se que houve perdas de $\mathrm{R} \$ 14.192,4$ e R $\$ 25.373,6$, respectivamente. Ao comparar as rendas líquidas obtidas com o clone Macaquinho observou-se que foi melhor o cultivo com duas amontoas porque induziria aumento de $\mathrm{R} \$$ 6.784,6 em relação ao cultivo com uma amontoa e de $\mathrm{R} \$ 11.181,2$ ao sem amontoa.

Tabela 4. Análise econômica de clones de taro cultivados sob diferentes números de amontoas.

\begin{tabular}{lccccc}
\hline Clones & $\begin{array}{c}\text { Número de } \\
\text { amontoas }\end{array}$ & $\begin{array}{c}\text { Produção } \\
\text { comercial } \\
\left(\mathrm{t} \mathrm{ha}^{-1}\right)\end{array}$ & $\begin{array}{c}\text { Renda bruta } \\
\left(\mathrm{R} \$ \mathrm{ha}^{-1}\right)\end{array}$ & $\begin{array}{c}\text { Custo total } \\
\left(\mathrm{R} \$ \mathrm{ha}^{-1}\right)\end{array}$ & $\begin{array}{c}\text { Renda liquida } \\
\left(\mathrm{R} \$ \text { ha }^{-1}\right)\end{array}$ \\
\hline \multirow{3}{*}{ Chinês } & 0 & 10,7 & $12.792,0$ & $6.169,9$ & $6.622,1$ \\
& 1 & 7,1 & $8.460,0$ & $6.537,2$ & $1.922,8$ \\
& 2 & 9,8 & $11.784,0$ & $6.904,6$ & $4.879,4$ \\
\hline \multirow{3}{*}{ Macaquinho } & 0 & 22,3 & $26.808,0$ & $5.993,5$ & $20.814,5$ \\
& 1 & 26,3 & $31.572,0$ & $6.360,9$ & $25.211,1$ \\
\end{tabular}

Fonte: Elaboração dos autores.

A análise econômica deve ser feita para se conhecer em detalhes a estrutura produtiva da atividade e realizar as alterações necessárias ao aumento de sua eficiência (PEREZ JÚNIOR; OLIVEIRA; COSTA, 2006). Isso porque a rentabilidade consiste, na comparação da receita com o custo de produção determinando o lucro. Só haverá lucro se a atividade produtiva proporcionar retorno que supere o custo alternativo ou de oportunidade (VILELA; MACEDO, 2000).

\section{Conclusões}

O cultivo do taro 'Macaquinho', com duas amontoas apresentou melhor desempenho agroeconômico.

\section{Agradecimentos}

Ao CNPq, pelas bolsas concedidas e à FUNDECT-MS, pelo apoio financeiro.

\section{Referências}

CARMO, C. A. S.; PUIATTI, M. Avaliação de clones de taro para cultivo no Estado do Espírito Santo. Horticultura Brasileira, Brasília, v. 22, p. 430, 2004. Suplemento 2.

FAOSTAT. CFAO Statistics Division 2009. Disponível em: <http://faostat.fao.org $>$. Acesso em: 18 aug. 2009.

GONDIM, A. R. O.; PUIATTI, M.; CECON, P. R.; FINGER, F. L. Crescimento, partição de fotoassimilados e produção de rizomas de taro cultivado sob sombreamento artificial. Horticultura Brasileira, Brasília, v. 25, n. 3, p. 418-428, 2007. 
HELMICH, M. Número de fileiras no canteiro na produção e rentabilidade de quatro clones de taro (Colocasia esculenta (L.) Schott). 2010. Dissertação (Mestrado em Agronomia) - Universidade Federal da Grande Dourados, Dourados.

HEREDIA ZÁRATE, N. A.; CASALI, V. W. D.; ALVAREZ VENEGAS, V. H. Rentabilidade das culturas de inhame 'Macaquinho' e 'Chinês', em cinco populações e cinco épocas de colheita. In: ENCONTRO NACIONAL SOBRE A CULTURA DO INHAME, 1., 1987, Viçosa. Anais... Viçosa: UFV, 1994, v. 1, p. 23-26.

HEREDIA ZÁRATE, N. A.; VIEIRA, M. C. Hortas: conhecimento básicos. Dourados: UFMS. 2005. 61 p.

HEREDIA ZÁRATE, N. A.; VIEIRA, M. C.; FACCO, R. C. Produção de clones de inhame em função do tamanho das mudas. Acta Scientiarum: Agronomy, Maringá, v. 25, n. 1, p. 183-186, 2003a.

HEREDIA ZÁRATE, N. A.; VIEIRA, M. C.; GRACIANO, J. D.; GIULIANI, A. R.; HELMICH, M.; GOMES, H. E. Produção e renda bruta de quatro clones de taro cultivados em Dourados, Estado do Mato Grosso do Sul. Acta Scientiarum. Agronomy, Maringá, v. 31, n. 2, p. 301-305, 2009a.

HEREDIA ZÁRATE, N. A.; VIEIRA, M. C.; ROSA JÚNIOR, E. J.; ALVES, J. C. Cama-de-frango de corte semidecomposta na produção dos taros Chinês e Macaquinho. Acta Scientiarum. Agronomy, Maringá, v. 25, n. 1, p. 177-181, 2003 b.

HEREDIA ZÁRATE, N. A.; VIEIRA, M. C.; ROSA JUNIOR, E. J.; SILVA, C. G. Forma de adição ao solo da cama-de-frango de corte semidecomposta para produção de taro. Pesquisa Agropecuária Tropical, Goiânia, v. 34, n. 2, p. 111-117, 2004.

HEREDIA ZÁRATE, N. A.; VIEIRA, M. C.; SOUSA, T. M.; RAMOS, D. D. Produção e renda líquida de milho verde em função da época de amontoa. Semina: Ciências Agrárias, Londrina, v. 30, n. 1, p. 95-100, 2009b.

KUROSAWA, C. Inhame. Disponível em: <http:// globoruraltv.globo.com/GRural/0,27062,LTP0-4373-0L-I,00.html>. Acesso em: 26 out. 2009.

LARCHER, W. Ecofisiologia vegetal. Tradução Carlos Henrique Britto de Assis Prado. 2. ed. São Carlos: RiMa Artes e Textos, 2004, $531 \mathrm{p}$.

MELO, A. S.; COSTA, B. C.; BRITO, M. E. B.; AGUIAR NETTO, A. O.; VIÉGAS, P. R. A. Custo e rentabilidade na produção de batata-doce nos perímetros irrigados de Itabaiana-Sergipe. Pesquisa Agropecuária Tropical, Goiânia, v. 39, n. 2, p. 119-123, 2009.
OLIVEIRA, F. L.; GUERRA, J. G. M.; ALMEIDA, D. L.; RIBEIRO, R. L. D.; SILVA, E. D.; SILVA, V. V.; ESPINDOLA, J. A. A. Desempenho de taro em função de doses de cama de aviário, sob sistema orgânico de produção. Horticultura Brasileira, Brasília, v. 26, n. 2, p. 149-153, 2008.

OLIVEIRA, F. L.; RIBEIRO, R. L. D.; SILVA, V. V.; GUERRA, J. G. M.; ALMEIDA, D. L. Desempenho do inhame (taro) em plantio direto e no consórcio com crotalária, sob manejo orgânico. Horticultura Brasileira, Brasília, v. 22, n. 3, p. 638-641, 2004.

PEREIRA, F. H. F.; PUIATTI, M.; MIRANDA, G. V.; SILVA, D. J. H.; FINGER, F. L. Divergência genética entre acessos de taro. Horticultura Brasileira, Brasília, v. 22, n. 1, p. 55-60, 2004.

PEREZ JUNIOR, J. H.; OLIVEIRA, L. M.; COSTA, R. G. Gestão estratégica de custos. 5. ed. São Paulo: Atlas, 2006, $378 \mathrm{p}$.

PUIATTI, M.; FÁVEIRO, C.; PEREIRA, F. H. F.; AQUINO, L. A.; GONDIM, A. R. O. Produção de taro chinês em função de número de época e número de amontoa. In: CONGRESSO BRASILEIRO DE OLERICULTURA, 45., 2005, Fortaleza. Resumos... Fortaleza: UFC, p. 76.

SAEG. Sistema para análises estatística, versão 9.1. Fundação Arthur Bernardes.Viçosa: UFV, 2007.

SILVA, E. E.; DE-POLLI, H.; GUERRA, J. G. M.; AZEVEDO, P. H. S.; TEIXEIRA, M. G.; ESPINDOLA, J. A. A.; ALMEIDA, M. M. T. B. Consórcio de inhame (taro) e crotalária em sistema orgânico de produção. Seropédica: Embrapa Agrobiologia, 2006. (Comunicado técnico, 88).

TAIZ, L.; ZEIGER, E. Fisiologia vegetal. Tradução Eliane Romanato Santarém. 3. ed. Porto Alegre: Artmed, 2004, 719 p.

TERRA, E. R.; HEREDIA ZÁRATE, N. A.; VIEIRA, M. C.; MENDONÇA, P. S. M. Proposta de cálculo e forma de adubação, com e sem amontoa, para a produção e renda do milho Superdoce 'Aruba'. Acta Scientiarum. Agronomy, Maringá, v. 28, n. 1, p. 7582, 2006.

VILELA, N. J.; MACEDO, M. M. C. Fluxo de poder no agronegócio: o caso das hortaliças. Horticultura Brasileira, Brasília, v. 18, n. 2, p. 8894, 2000. 